\title{
COMPORTAMENTO DE PLANTAS DE CAFÉ ARÁBICA SUBMETIDAS A DÉFICIT HÍDRICO DURANTE O DESENVOLVIMENTO INICIAL
}

\author{
BEHAVIOR OF COFFEA ARABICA L. PLANTS EXPOSED TO WATER DEFICITS \\ IN DIFFERENT PHASES OF THEIR INITIAL DEVELOPMENT
}

\author{
Gustavo Sessa Fialho ${ }^{1}$; Danilo Paulúcio Da Silva ${ }^{2}$; Edivaldo Fialho Dos Reis ${ }^{3}$; \\ Aymbiré Francisco Almeida Da Fonseca ${ }^{4}$; Maria Amélia Gava Ferrão ${ }^{5}$
}

\begin{abstract}
RESUMO
O presente trabalho objetivou estudar a influência do déficit hídrico no desenvolvimento inicial da lavoura cafeeira, aplicado em diferentes épocas: 30, 60, 90 e 120 dias após o transplantio. O experimento foi conduzido em casa de vegetação, em delineamento inteiramente ao acaso, com cinco tratamentos e três repetições. Os tratamentos consistiram na submissão das mudas transplantadas a déficits hídricos com duração fixa de 30 dias, sendo D0 = sem déficit hídrico; D1 = plantas submetidas a déficit hídrico entre o $30^{\circ}$ e $60^{\circ}$ dia após o transplantio; D2 = plantas submetidas a déficit hídrico entre o $60^{\circ}$ e $90^{\circ}$ dia após o transplantio; D3 = plantas submetidas a déficit hídrico entre o $90^{\circ}$ e $120^{\circ}$ dia após o transplantio e; D4 = plantas submetidas a déficit hídrico entre o $120^{\circ} \mathrm{e}$ $150^{\circ}$ dia após o transplantio. Após 180 dias do transplantio avaliou-se a massa seca da parte aérea e do sistema radicular, a área foliar, o diâmetro da copa e altura das plantas. O efeito do déficit hídrico foi especialmente importante nas variáveis estudadas quando aplicado aos 30, 60 ou 90 dias após o transplantio e não influenciou de forma significativa as variáveis área foliar, diâmetro da copa e altura das plantas, quando aplicado aos 120 dias após o transplantio.
\end{abstract}

Palavras chave: Estresse hídrico, Coffea arabica, cafeicultura irrigada.

\begin{abstract}
The objective of this work was to study the influence of water deficits on the initial development of a coffee field, applied at different times: 30, 60, 90 and 120 days after transplanting. The experiment was conducted in a greenhouse, with a completely randomized design, with five treatments and three repetitions. Treatments consisted of submission of transplanted seedlings to water deficits of fixed duration of 30 days, with $D_{0}=$ without water deficit, $D_{1}=$ plants submitted to water deficits between 30 and 60 days after transplanting, $D_{2}=$ plants submitted to water deficits between 60 and 90 days after transplanting, $D_{3}=$ plants submitted to water deficits between 90 and 120 days after transplanting and, $D_{4}=$ plants submitted to water deficits between 120 and 150 days after transplanting. At 180 days after transplanting we evaluated aerial and root system dry mater, leaf area, canopy diameter, and plant height. The effect of water deficit was especially important on the variables studied when applied 30, 60 or 90 days after transplanting and did not significantly influence the variables leaf area, canopy diameter, and plant height, when applied 120 days after transplanting.
\end{abstract}

Key words: Water stress, arabica coffee, irrigated coffee production.

\section{INTRODUÇÃO}

O Brasil é o maior produtor mundial de café com cerca de 29,5\% da produção global (Agrianual,
2008). Segundo dados da Companhia Nacional de Abastecimento-CONAB (2008), o parque cafeeiro brasileiro em produção é formado por mais de 5,6 bilhões de plantas cultivadas em 2,1 milhões

\footnotetext{
1 Eng. Agr ${ }^{\circ}$., mestrando, Dept ${ }^{\circ}$ Fitotecnia/Universidade Federal de Viçosa (UFV), Viçosa-MG. Brasil. CEP: $36570-000$ HYPERLINK “mailto:gsfialho@hotmail.com” gsfialho@hotmail.com

2 Eng.Agr ${ }^{\circ}$., mestrando, Dept ${ }^{\circ}$ Engenharia Agrícola/UFV, Viçosa-MG. Brasil.

3 Prof. Adjunto, Dept ${ }^{\circ}$ Engenharia Rural/Universidade Federal do Espírito Santo (UFES), Alegre-ES. Brasil.

4 Pesquisador-Empresa Brasileira de Pesquisa Agropecuária (Embrapa Café)/, Brasília, DF. Brasil

5 Pesquisadora-Embrapa Café/ Instituto Capixaba de pesquisa Assistência Técnica e extensão Rural (Incaper), Vitória-ES. Brasil.
} 
de hectares, que no ano de 2007 produziram 33,7 milhões de sacas beneficiadas de café e destas, $69,7 \%$ foram provenientes de cafeeiros da espécie

\section{Coffea arabica.}

As condições climáticas adversas predominantes no ano agrícola de 2007, caracterizadas por uma deficiência hídrica acentuada e prolongada nas principais regiões produtoras de café do país, afetaram fortemente tanto a formação quanto o potencial produtivo das lavouras cafeeiras causandoas desfolhamento e floradas irregulares. Bierhals e Ferroni (2008), destacam que nos dias atuais, a seca é o problema que mais tem afetado a cafeicultura brasileira colocando em risco as previsões de futuras safras.

Lecoeur e Sinclair (1996) salientam que, quando as plantas cultivadas passam por um processo de déficit hídrico o seu crescimento e desenvolvimento é comprometido. Deste modo, Gervásio e Lima (1998) constataram que na fase inicial de formação do cafeeiro arábica, cultivar Icatu MG 3282, com seis meses de idade, plantado em vasos, o aumento da umidade do solo acelerou o desenvolvimento da planta.

A água é fator fundamental na produção vegetal, sua falta ou seu excesso, afeta de maneira decisiva, o desenvolvimento das plantas (Meurer, 2007). Assim, Camargo (1989) e Gutierrez e Meinzer (1994), sugerem que estimativas precisas da necessidade de água para o cafeeiro são essenciais, pois a escassez da mesma pode reduzir substancialmente o crescimento da planta sem que com isso nelas perceba-se sinais de murchamento.

A crescente modernização da agricultura brasileira tem exigido de seus diferentes segmentos mudanças profundas no sentido da racionalização do processo produtivo (Marcondes et al., 2005). Neste sentido, o uso racional da irrigação tem crescido em função dos problemas de estiagens em áreas tradicionais utilizadas para a implantação de cafeeiros e em novas regiões climaticamente marginais, onde o déficit hídrico anual é superior a 120-150 mm (Matiello, 1999). Ainda de acordo com Matiello (1995), para garantir o sucesso na formação da lavoura cafeeira é imprescindível, sempre que necessário, realizar a suplementação com água no pós-plantio das mudas, evitando-se o estresse hídrico e permitindo o bom pegamento das mesmas.

Pelo exposto, fica clara a importância da realização de estudos relativos ao efeito do estresse hídrico durante o desenvolvimento inicial da lavoura cafeeira, o que justifica a condução de trabalhos de pesquisa de maneira que se possa encontrar saídas para tal impasse agronômico.

O presente trabalho objetivou estudar a influência do déficit hídrico no desenvolvimento inicial de cafeeiros da espécie Coffea arabica.

\section{MATERIAL E MÉTODOS}

O experimento foi instalado na casa de vegetação do Centro de Ciências Agrárias da Universidade Federal do Espírito Santo (CCA-UFES), localizado no município de Alegre/ES, latitude $20^{\circ} 45^{\prime} \mathrm{Sul}$, longitude $41^{\circ} 48^{\prime}$ Oeste e altitude de $150 \mathrm{~m}$.

Utilizou-se mudas da espécie Coffea arabica, variedade Catuaí Vermelho IAC 44, que foram produzidas em sacos plásticos, com dimensões de 20 $\mathrm{cm}$ de altura por $11 \mathrm{~cm}$ de largura e posteriormente transplantadas para recipientes com volume de 12 litros contendo solo de textura média. Este foi destorroado, peneirado (4 $\mathrm{mm}$ de malha) e homogeneizado. De acordo com sua análise química, teve o $\mathrm{pH}$ corrigido por meio de uma calagem e foi adubado seguindo as recomendações básicas para a cultura do café.

O experimento foi montado em delineamento inteiramente casualizado com cinco tratamentos e três repetições.

Os tratamentos consistiram na submissão das mudas recém transplantadas a déficits hídricos com período de duração fixo de 30 dias, sendo $\mathrm{D}_{0}=$ sem déficit hídrico, $\mathrm{D}_{1}=$ plantas submetidas a déficit hídrico entre o $30^{\circ}$ e $60^{\circ}$ dia após o transplantio, $\mathrm{D}_{2}=$ plantas submetidas a déficit hídrico entre o $60^{\circ}$ e $90^{\circ}$ dia após o transplantio, $D_{3}=$ plantas submetidas a déficit hídrico entre o $90^{\circ}$ e $120^{\circ}$ dia após o transplantio e, $\mathrm{D}_{4}=$ plantas submetidas a déficit hídrico entre o $120^{\circ}$ e $150^{\circ}$ dia após o transplantio.

Avaliou-se a massa seca da parte aérea e do sistema radicular, área foliar, diâmetro da copa e altura das plantas. Para as mensurações das referidas variáveis utilizou-se: régua milimetrada e balança analítica, sendo que para a determinação da massa seca, o material vegetal foi submetido à temperatura de $80{ }^{\circ} \mathrm{C}$ por um período de 72 horas em estufa e, para a determinação da área foliar utilizou-se o medidor de área foliar LAI-3100. As variáveis estudadas foram avaliadas 180 dias após o transplantio das mudas. 
Os dados foram submetidos à análise de variância, sendo as médias agrupadas pelo teste de Scott e Knott em nível de 5\% de probabilidade, utilizando-se o aplicativo computacional em genética e estatística, denominado programa GENES (Cruz, 2006).

\section{RESULTADOS E DISCUSSÃO}

De acordo com Fontes et al. (2005) a medida do acúmulo de matéria orgânica considerando-se a massa das partes secas das plantas (frutos, caules, folhas e outros) é o fundamento para se analisar o crescimento. Deste modo, no que diz respeito à massa seca das plantas de café, o tratamento no qual a suspensão do fornecimento de água ocorreu aos 120 dias após o transplantio das mudas (D4), foi o que menos impactou a produção de massa seca da parte aérea, apresentando uma redução de 13,8 \%, em relação àquelas não submetidas à ausência da irrigação (D0) (Figura 1). Isto provavelmente deveu-se, ao fato de que as plantas naquela ocasião, apresentavam o sistema radicular mais desenvolvido e, consequentemente, com a capacidade de exploração de maior volume de solo.

Por sua vez, os tratamentos nos quais a suspensão da irrigação ocorreu aos 30, 60 e 90 dias após o transplantio das mudas D1, D2, e D3, foram aqueles que mais influenciaram a produção de massa seca da parte aérea das plantas, que tiveram o seu valor reduzido em média $62,03 \%$, não tendo sido observadas diferenças significativas entre as médias dos mesmos (Figura 1). Silva et al. (2006), avaliando aos 90 dias após o transplantio plantas de coffea arabica var. bourbon vermelho sob diferentes turnos de rega, observaram um efeito ainda mais severo do estresse hídrico e, concluíram que as plantas expostas a um turno de rega de 21 dias apresentaram um decréscimo na produção de massa seca da parte aérea de $81,4 \%$ em relação àquelas expostas a um turno de rega de sete dias.

Nos tratamentos D1, D2, D3 e D4, correspondentes ao déficit hídrico aplicado aos 30, 60, 90 e 120 dias após o transplantio das mudas, ocorreu uma expressiva redução da produção de massa seca do sistema radicular das plantas, que tiveram seu valor reduzido em $65,3 \%, 53,3 \%, 70 \%$ e $47,9 \%$, respectivamente (Figura 2). Muito embora, as médias obtidas nos citados tratamentos não tenham diferido entre si, nota-se a tendência de ser o tratamento

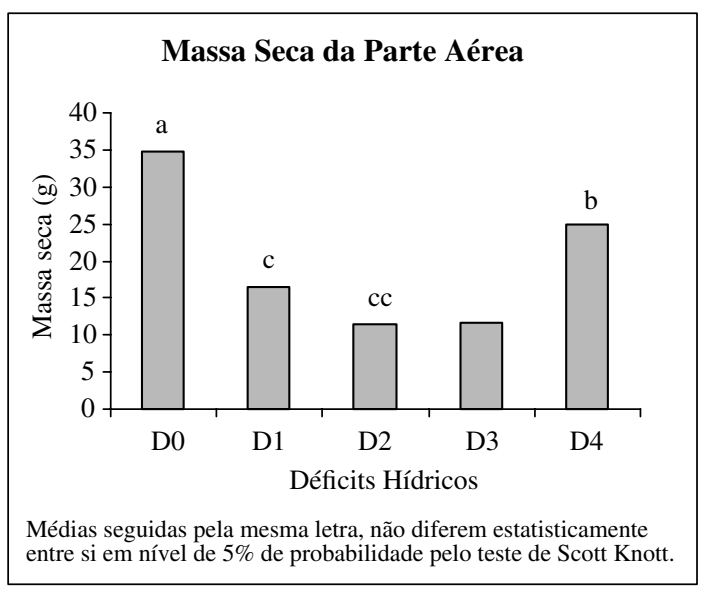

Figura 1. Massa seca da parte aérea (A) aos 180 dias após o transplantio, das plantas de Coffea arabica var. Catuaí Vermelho IAC 44, submetidas a déficit hídrico por um período fixo de 30 dias, aos 30, 60, 90 e 120 dias após o transplantio, $\mathrm{D}_{1}, \mathrm{D}_{2}, \mathrm{D}_{3}$ e $\mathrm{D}_{4}$, respectivamente.

D4, aquele que menos influenciou para a redução da produção de massa seca do sistema radicular, o que esteve relacionado ao fato de que, ao receberem o déficit hídrico, as plantas desse tratamento já apresentavam-se mais desenvolvidas e melhor estabelecidas.

\section{Massa Seca do Sistema Radicular}

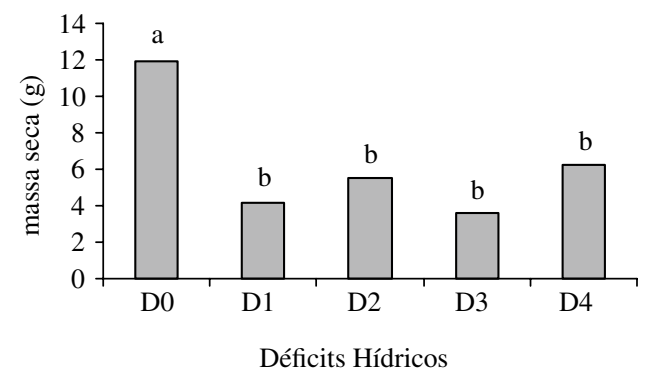

Médias seguidas pela mesma letra, não diferem estatisticamente entre si em nível de 5\% de probabilidade pelo teste de Scott Knott.

Figura 2. Massa seca do sistema radicular aos 180 dias após o transplantio, das plantas de Coffea arabica var. Catuaí Vermelho IAC 44, submetidas a déficit hídrico por um período fixo de 30 dias, aos 30, 60, 90 e 120 dias após o transplantio, $\mathrm{D}_{1}, \mathrm{D}_{2}, \mathrm{D}_{3}$ e $\mathrm{D}_{4}$, respectivamente.

Para área foliar, não houve diferença entre as plantas que receberam o déficit hídrico aos 120 após o transplantio $D_{4}$, e aquelas que não o receberam $D_{0}$ (Figura 3), ficando bem claro que a influência da 
suspensão da irrigação por 30 dias, sobre a redução da área foliar das plantas de café recém implantadas, foi maior quando da aplicação do déficit hídrico aos 30,60 e 90 dias após o transplantio, tratamentos: $\mathrm{D}_{1}$, $\mathrm{D}_{2}$, e $\mathrm{D}_{3}$, respectivamente, que apresentaram uma redução média na área foliar de $61,56 \%$ em relação ao tratamento $\mathrm{D}_{0}$, muito embora, os três tratamentos não tenham diferido entre si, (Figura 3).

Plantas com maior área foliar, apresentam condições de maior realização de fotossíntese e com isso, tendem a produzir maior quantidade de massa seca da parte aérea, caso das plantas do tratamento $\mathrm{D}_{4}$, (Figuras 3 e 1 ).

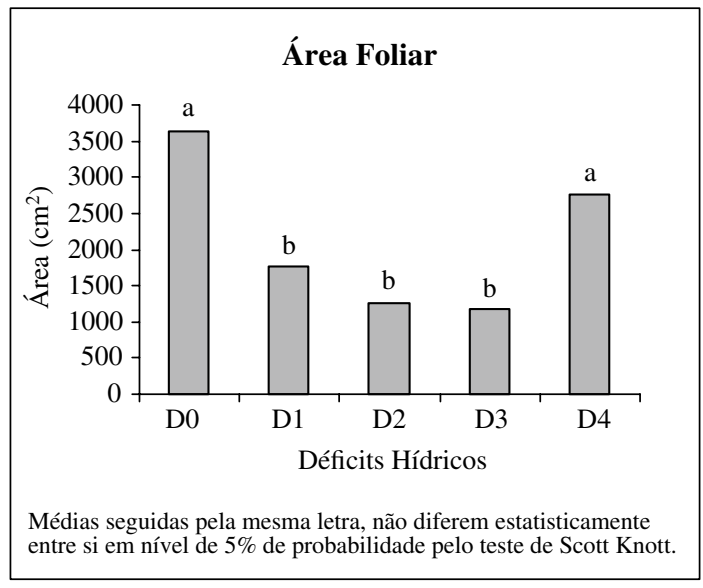

Figura 3. Área foliar, aos 180 dias após o transplantio, das plantas de Coffea arabica var. Catuaí Vermelho IAC 44 submetidas a déficit hídrico por um período fixo de 30 dias, aos 30, 60, 90 e 120 dias após o transplantio, $\mathrm{D}_{1}, \mathrm{D}_{2}, \mathrm{D}_{3}$ e $\mathrm{D}_{4}$, respectivamente.

À semelhança do que ocorreu com a área foliar, não houve diferença entre o tratamento onde o déficit hídrico ocorreu aos 120 após o transplantio $\left(\mathrm{D}_{4}\right)$ e o que não recebeu déficit $\left(D_{0}\right)$ para as variáveis diâmetro da copa e a altura das plantas, (Figuras 4 e 5). As plantas que tiveram redução no diâmetro de sua copa e em sua altura, também foram aquelas dos tratamentos onde a aplicação do déficit hídrico ocorreu aos 30, 60 e 90 dias após o transplantio $\left(\mathrm{D}_{1}, \mathrm{D}_{2}, \mathrm{e} \mathrm{D}_{3}\right.$, respectivamente), e embora dentro de cada variável os três tratamentos não tenham diferido entre si, diferiram em relação ao tratamento $\mathrm{D}_{0}$, apresentando uma redução média de $28,9 \%$ no diâmetro da copa e de 18,3\% na altura das plantas (Figuras 4 e 5). Santana et al. (2004) estudando o desenvolvimento inicial de Coffea arabica cultivares IAPAR-59 e Obatã em regime adensado, constataram que as plantas submetidas ao tratamento com irrigação apresentaram valores da altura significativamente superior às plantas submetidas aos tratamentos sem uso de irrigação, evidenciando a importância desse prática no crescimento inicial do cafeeiro.

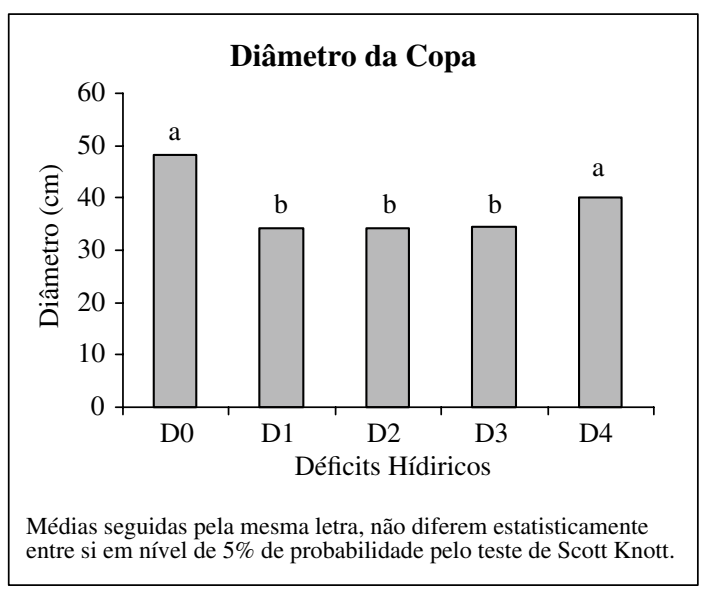

Figura 4. Diâmetro da copa aos 180 dias após o transplantio, das plantas de Coffea arabica var. Catuaí Vermelho IAC 44 submetidas a déficit hídrico por um período fixo de 30 dias, aos $30,60,90$ e 120 dias após o transplantio, $D_{1}, D_{2}, D_{3}$ e $D_{4}$, respectivamente.

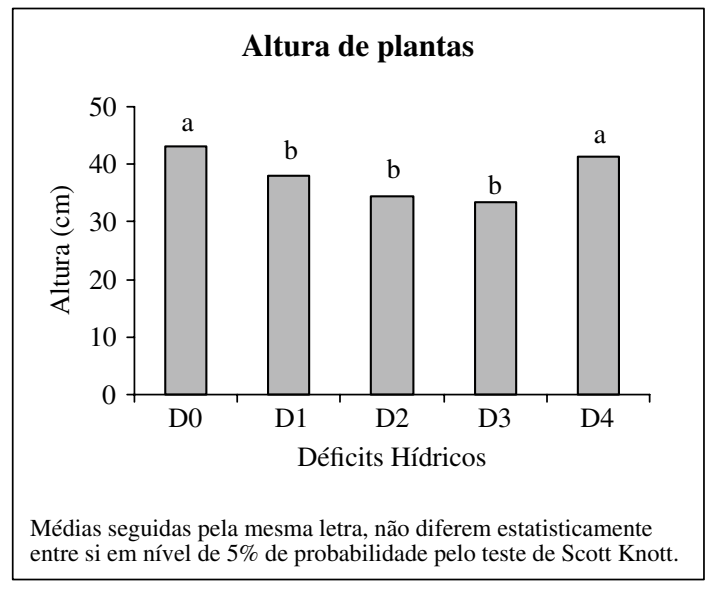

Figura 5. Altura das plantas (B), aos 180 dias após o transplantio, das plantas de Coffea arabica var. Catuaí Vermelho IAC 44 submetidas a déficit hídrico por um período fixo de 30 dias, aos 30, 60, 90 e 120 dias após o transplantio, D1, D2, D3 e D4, respectivamente.

\section{CONCLUSÕES}

- O déficit hídrico fixo de 30 dias aplicado após o $30^{\circ}, 60^{\circ}$ e $90^{\circ}$ dias após o transplantio das mudas proporcionou expressiva redução da produção de massa seca da parte aérea, da 
área foliar, do diâmetro da copa e da altura das plantas do cafeeiro;

- O déficit hídrico fixo de 30 dias, aplicado 120 dias após o transplantio das mudas, não influenciou a área foliar, o diâmetro da copa e a altura das plantas, tendo sido ainda, o que menos influenciou na produção massa seca da parte aérea;

- Constatou-se que um período de déficit hídrico fixo de 30 dias, causou perdas significativas

\section{REFERÊNCIAS BIBLIOGRÁFICAS}

AGRIANUAL 2008. Anuário da agricultura brasileira. São Paulo: FNP Consultoria, 2007, pp. 213-234.

BIERHALS, J. D.; FERRONI, P. H. C. Café: safra 2008/2009 encolhe e preços sobem. In: AGRIANUAL (2008): anuário da agricultura brasileira. São Paulo: FNP Consultoria, 2007, pp. 213-215.

CAMARGO, A.P. 1989. de. Necessidades hídricas do cafeeiro. In: Curso prático internacional de agrometeorologia, 3. ed. Campinas: IAC, $20 \mathrm{p}$.

COMPANHIA NACIONAL DE ABASTECIMENTOCONAB. 2008. Acompanhamento da safra brasileira: café, safra 2008, primeira estimativa, janeiro/2008. Brasília: Conab, $10 \mathrm{p}$.

CRUZ, C.D. 2006. Programa GENES: estatística experimental e matrizes. Editora UFV: Viçosa, 480 p.

FONTES, P.C.R.; DIAS, E.N.; SILVA, D.J.H. 2005. Dinâmica do crescimento, distribuição de massa seca na planta e produção de pimentão em ambiente protegido. Horticultura Brasileira, Brasília, v. 23, n. 1, p. 94-99.

GERVÁSIO, E.S.; LIMA, L.A. 1998. Desenvolvimento do cafeeiro (Coffea arabica L.) em função de diferentes lâminas de água aplicadas durante a fase inicial de formação da lavoura. Revista Brasileira de Engenharia Agrícola e Ambiental, Campina Grande, v. 2, n. 1, p. 68-74.

GUTIÉRREZ, M.V.; MEINZER, F.C. 1994. Estimating water use and irrigation requirements of coffee in Hawaii. Journal of American Society of Horticulture Science, v. 119, n. 3, p. 652-657. em plantas de coffea arabica L. nas diferentes fases de seu desenvolvimento inicial.

\section{AGRADECIMENTOS}

Os autores expressam seus agradecimentos ao Dr. Mark Kulig pela colaboração na elaboração desse trabalho.

LECOEUR, J.; SINCLAIR, R.T. 1996. Field pea transpiration and leaf growth in response to soil water deficits. Crop Science, Madison, v. 36, p. 331-335.

MARCONDES, M.C.; MIGLIORANZA, E.; FONSECA, I.C.B. 2005. Danos mecânicos e qualidade fisiológica de semente de soja colhida pelo sistema convencional e axial. Revista Brasileira de Sementes, v. 27, n. 2, p. 125-129.

MATIELLO, J.B. 1995. Café produtivo na montanha. A lavoura. n. 615. pp. 36-47.

MATIELLO, J.B. 1999. Quentes como o café: indicações de uso de equipamentos, produtos e serviços para a cafeicultura. Rio de Janeiro: MAA/PROCAFÉ, 185 p.

MEURER, E.J. 2007. Fatores que influenciam o crescimento e o desenvolvimento das plantas. In: NOVAIS, R. F.; ALVAREZ V., V. H.; BARROS, N. F.; CANTARUTTI, R. B.; NEVES, J. C. L. (Eds.). Fertilidade do Solo. Sociedade Brasileira de ciências do solo: Viçosa, MG, 1.017 p.

SANTANA, MÁRCIO S.; OLIVEIRA, CARLOS A. DA S.; QUADROS, MICHAEL. 2004. Crescimento inicial de duas cultivares de cafeeiro adensado influenciado por níveis de irrigação localizada. Engenharia Agrícola, Jaboticabal, v. 24, n. 3, p. 644-653.

SILVA, D.P.; FIALHO, G.S.; REIS, E.F.; PEZZOPANE, J. E.M.; POLANCZYK, R. A.; SILVA, E.D. 2006. Efeito de diferentes dosagens de hidroabsorvente e turnos de rega no desenvolvimento inicial do café arábica. In: Congresso Brasileiro de Engenharia Agrícola, 35, 2006, João Pessoa, PB. Anais... João Pessoa: SBEA. 
